\title{
Carbon Nanofibers: Evaluation of Life Cycle Environmental Impacts
}

\author{
Vikas Khanna and Nikki Campion \\ Department of Civil and Environmental Engineering, University of Pittsburgh, \\ Benedum Hall, Pittsburgh, PA \\ United States of America
}

\section{Introduction}

The rapidly evolving field of nanotechnology has sparked a great level of interest and enthusiasm from the research and industrial community. Given the enormous promise that engineered nanomaterials and nanoproducts offer, it is essential to investigate the potential life cycle environmental impacts of emerging nanotechnologies for guiding their sustainable development. One rapidly emerging class of engineered nanoscale materials is carbon nanofibers (CNFs). While studies regarding the toxicological impacts of CNFs are needed, holistic understanding of the impact of CNFs and nanoproducts using systems analysis is central for their safe and sustainable development. Systems analysis with life cycle thinking offers a good tool for evaluating the broader impacts of emerging technologies at an early stage of research. This chapter will examine the needs, challenges, and promises of life cycle assessment (LCA) in the evaluation of CNFs and CNF-based products. A general introduction to LCA is explained in the first part of the chapter and the challenges and promises for the LCA of nanoproducts are identified. The use of LCA in guiding sustainable development of nanotechnology is illustrated in greater detail with a discussion on LCA of CNFs in section 2. Section 3 describes the life cycle energetic impacts of the use of CNFbased polymer composites in auto body panels as a potential replacement for traditional materials. A brief discussion of the toxicological impacts of CNFs is presented in section 4 . Section 5 summarizes the major findings and provides directions for future research.

Nanotechnology is a fast emerging technology with large number of consumer goods containing engineered nanomaterials already in production [1,2]. The potential impact of nanotechnology derives from the fact that unprecedented material properties are being discovered in nanoscale materials that enable a broad spectrum of novel applications. One such class of materials is carbonaceous nanomaterials. The last 25 years have seen the discovery of a variety of carbonaceous nanomaterials including fullerenes, nanotubes, nanohorns, and nanofibers [3]. Carbon Nanofibers (CNFs) belong to a new class of materials that have exceptional mechanical properties like high tensile strength $(12000 \mathrm{MPa})$ that is approximately 10 times that of steel [4,5]. Besides mechanical strength, CNFs possess novel electrical properties like high electrical conductivity. These properties of CNFs are being explored in a variety of ways by imparting functionalities in various intermediate and final value-added consumer products. Applications include the use of CNFs as reinforcements for high strength polymer nanocomposites, use in carbon-lithium batteries, and electrically 
conducting polymers [5]. High specific surface area of these fibers is an additional attribute that has been investigated for use of CNFs as catalyst support material especially for liquid phase reactions [4].

Although altered physicochemical properties make CNFs and CNF-based nanoproducts commercially attractive, they also raise concerns about the human and ecosystem impact of these materials [6-11]. While toxicological studies of CNFs are important, holistic evaluation of emerging CNF-based nanoproducts using systems analysis is critical for assessing their environmental sustainability and impact on human health. The need for combining a holistic systems view with reductionist research has been identified to reduce the chance of unpleasant surprises due to emerging technologies such as nanotechnology [12-14]. Despite the availability of methods for such holistic analysis, very few such studies have been carried out on nanoproducts [15]. Among systems analysis methods, life cycle assessment (LCA) has been popular and practical for understanding the environmental impact associated with a product or a process over its entire life cycle and offers great potential for understanding the life cycle environmental impacts of emerging nanomaterials and nanoproducts. The following sub-section provides a detailed discussion about the LCA methodology along with the challenges and benefits of LCA of emerging nanoproducts.

\subsection{Life cycle assessment (LCA)}

\subsubsection{Methodology}

LCA is an approach to quantify the environmental impact of a product or a process over its entire life cycle. The methodology is standardized via. ISO 14040 and 14044 . The LCA methodology involves four steps [16, 17]. Figure 1 presents a schematic description of the different phases in a typical LCA. The four phases are briefly discussed below.

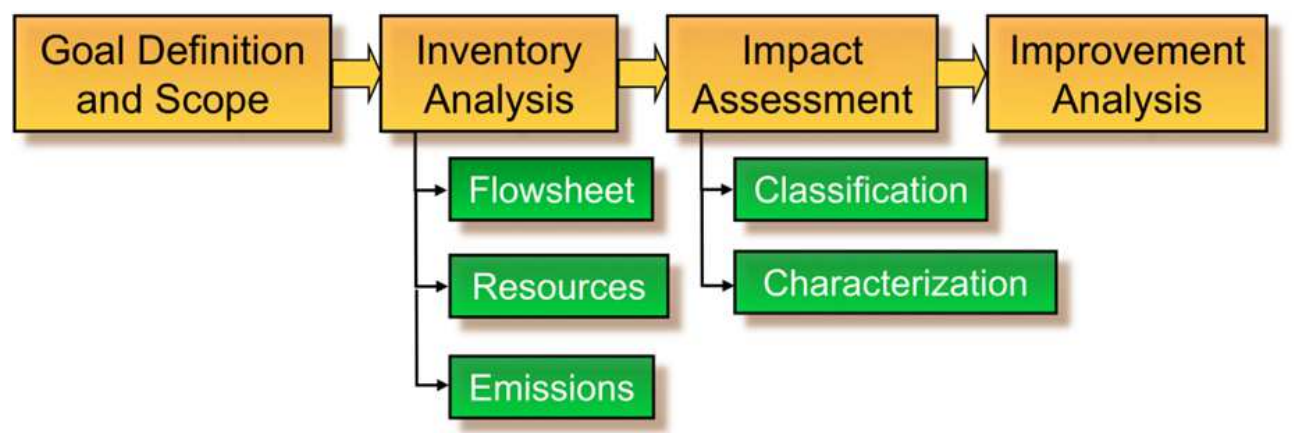

Fig. 1. Phases of a Typical LCA.

Goal and Scope Definition- The goal and scope definition involves defining the boundaries of the LCA study and specifies which processes are included in the study. In general, the scope of an LCA study consists of resource extraction, material and energy inputs synthesis, product manufacture, waste treatment, packaging, transportation, product use, and end-oflife phase of a product. Such an analysis is termed as "Cradle-to-grave". The purpose of the LCA study is clearly stated in this phase. This can be either comparative assessment of nanoproducts vs. alternatives, evaluation of a nanoproduct with different synthesis routes, and/or a single nanoproduct for a new application. This aids in defining the appropriate functional unit for the study resulting in a fair comparison. As an example, consider the life 
cycle environmental comparison of plastic vs. paper grocery bags. One paper bag may physically hold the same amount of groceries as two plastic bags. Thus the appropriate functional unit in this case should be the comparison of one paper bag vs. two plastic bags. Once the appropriate functional unit is defined, the process boundary should be specified clearly to define the scope of the LCA study. Proper care and vigilance are crucial during the process boundary selection to yield meaningful and interpretable results. In addition, doing multiple studies with different boundaries to determine the effect of the boundary limits can be helpful in certain situations. The life cycle practitioner should always state the purpose of the study and this usually helps in defining the boundary.

Inventory Analysis- This is the most resource-demanding phase of the LCA. It consists of identifying and collecting input and output data for each step in the life cycle of a product. There are several different ways of obtaining data for a typical LCA. Data sources typically include public or commercial LCA databases, published experimental data and LCA studies, propriety industrial data etc. National Renewable Energy Laboratory (NREL) Life Cycle Inventory database is an example of a public life cycle database. Several commercial LCA packages are also available. Some of the examples are SimaPro, Ecoinvent, GABI, and Umberto. Input data typically includes material and energy resources, labor, capital, and equipment. Output data consists of products, byproducts, and emissions of substances to air, water, and soil.

Impact Assessment- This phase involves classifying and characterizing emissions into various environmental impact categories to provide several indicators for analyzing the potential contributions of the resource extractions and wastes/emissions in an inventory to a number of potential impacts. The individual results for the different impact categories can be further normalized and weighed based on valuation techniques. Several Life Cycle Impact Assessment (LCIA) approaches exist and these have been described and critically assessed in detail in the literature [18]. The choice of which impact categories and hence impact assessment approach to use is a subjective one and at the discretion of the LCA practitioner.

The emissions from the complete life cycle of a product are available at the aggregate level. These are classified and characterized based on their impact into various impact categories often described as Midpoint Indicators. Common impact categories include Global Warming Potential, Acidification Potential, Eutrophication Potential, Human Toxicity Potential, Ozone Layer Depletion Potential and Photochemical Smog Formation Potential. Different chemicals may have a variety of different environmental impacts. For example, carbon dioxide results in global warming impact, Hydro Chloro-Fluoro Carbons have an adverse effect on ozone layer. Classification consists of combining different chemical impacts into a common metric. For example, $1 \mathrm{~kg}$ of methane has a global warming impact equivalent to $25 \mathrm{~kg}$ of carbon dioxide, similarly $1 \mathrm{~kg}$ of nitrous oxide has a global warming impact equivalent to $298 \mathrm{~kg}$ of carbon dioxide. Thus, the global warming potential characterization factors relative to carbon dioxide are 25 and 298 for methane and nitrous oxide respectively. These impacts are then expressed in terms of total equivalents of carbon dioxide to quantify the Global Warming Potential. Similar approach is followed for other impact categories. Characterization factors are available in the literature for a large number of chemicals and their impacts in various categories.

Interpretation- This is the phase in LCA where the results of the impact assessment are put together in a form that can be used directly to draw conclusions and make recommendations for improving the environmental performance of a product or the 
process. Sensitivity and or uncertainty analysis is particularly useful before this phase to quantify the impact of important parameters on the LCA results.

Although a data intensive approach, LCA has found wide use in the industry and many companies have found it appealing to employ LCA techniques as a way of moving beyond environmental compliance to create win-win business opportunities by improving the quality of their products while minimizing the environmental impact of their industrial operations.

\subsubsection{LCA: Challenges and benefits for emerging nanomaterial and nanoproduct}

Despite the fact that the LCA methodology is standardized via ISO 14040 and 14044 standards and pertinent software and inventory databases are available, the methodology faces several challenges. Some of these include getting high quality life cycle inventory data, combining data and emissions in disparate units and at multiple spatial and temporal scales, dealing with high dimensionality data, and dealing with processes having a range of emissions $[19,20]$. These challenges make it even more difficult to apply LCA to emerging technologies like nanotechnology. The need for the LCA of potential nanoproducts has been identified and discussed by researchers and various agencies [13, 21-24]. However, LCA of nanotechnology has progressed at a slow pace due to several formidable challenges. These are discussed below.

- $\quad$ Existing life cycle inventory databases are limited in scope and are useful for evaluating conventional products and processes.

- There is little publicly available information about the inputs and outputs of nanomanufacturing processes since most of the data is proprietary or available for laboratory scale operations.

- There is very little quantifiable data available on the human health and ecosystem impacts of engineered nanomaterials.

- Forecasting nanotechnology life cycle processes and activities is difficult since the technology is in its infancy and evolving rapidly.

LCA with its powerful toolbox can help address many critical concerns like material, energy, and environmental impact intensity of products, which complemented with the toxicological information of nanomaterials can help in sustainable development of nanotechnology. Some of the expected benefits of nanotechnology LCA are listed below:

- Identify phases in a nanoproduct's life cycle that have the maximum environmental impact and thus areas for improvement.

- Quantify how much of the energy savings and environmental impact during the use phase of nanoproducts are offset during their production phase.

- Identification of end-of-life scenarios and treatment options specific to nanoproducts.

- Evaluation of economic and environmental trade-offs of nanoproducts vs. conventional ones.

The data, results, and insights from LCA may be useful for identifying and allaying public concerns about emerging nanomaterials. It can also be used for risk assessment and as a screening tool for evaluating different technologies and product options.

\subsubsection{Life cycle inventory for emerging nanoproducts- overview}

The ISO methodology as outlined in ISO series 14040 and 14044 in general is applicable for evaluating potential nanoproducts and nanoprocesses. However, as mentioned in Section 
2.2, the major hindrance is the severe lack of life cycle data for nanomanufacturing. This subsection describes the general approach that can be followed for compiling the LCA of potential nanoproducts in the light of the challenges mentioned in the preceding sections.

Compiling life cycle inventory for nanomaterials and nanoproducts can be an excruciating and resource intensive task. This is because nanoprocesses are evolving rapidly and most of the industry data is proprietary. As a starting step, LCA practitioners can compile the life cycle inventory for nanoproducts based on laboratory experience and data available in the open literature. Wherever possible, plant specific data should be used. In the absence of any information, parallels can be drawn with similar technologies to get data on material and energy consumption. For example, the Chemical Vapor Deposition (CVD) process used for the synthesis of Carbon based nanomaterials, such as Single-Walled Carbon Nanotubes and CNFs is similar in nature to the CVD process used for chip manufacturing in the semiconductor industry. Missing data may be reconciled ensuring the satisfaction of conservation laws of mass and energy. Unlike traditional products and processes, additional information about the possible quantity and mode of release of nanoparticles is crucial for estimating the extent of human and ecological impact of nanoproducts. Various assumptions related to the boundary and selected processes should also be clearly stated. Since nanoproducts have only recently started penetrating the consumer market, information regarding the end-of-life of nanoproducts is missing. Sensitivity analyses based on different scenarios can provide useful insight and extreme bounds for the end-of-life impact of nanoproducts. The next section illustrates the use of life cycle approach in the environmental evaluation of one kind of engineered nanoparticles, CNFs.

\section{Carbon nanofibers}

\subsection{CNFs: Process description}

The avoidance of formation of carbon deposits has been of utmost importance in refinery applications like steam reforming of hydrocarbons, hydrocracking, hydrotreating etc. primarily because these carbon filaments leads to deactivation of the catalyst surface, blockage in reactor systems and reduction in heat transfer [4, 25]. However, in recent years, Carbon Nanofibers have received a great deal of attention both from the research and industrial community because of their novel properties that can be realized in a variety of ways in various applications. CNFs consist of monomolecular carbon fibers with diameters ranging from tens of nanometer to 200 nanometer. CNFs are characterized by high tensile strength $(12000 \mathrm{MPa})$ and high Young's modulus (600 GPa) that is approximately 10 times that of steel [5]. Besides mechanical strength, CNFs possess novel electrical properties like high electrical conductivity. Potential applications of CNFs include their use for lighter and stronger polymer nanocomposites and in electronic components. Several academic and industrial research groups have directed their efforts towards synthesizing and optimizing the growth of these CNFs. The catalytic synthesis of CNFs consists of formation of these fibers on metallic catalysts. The process consists of reduction of the catalyst sample in a hydrogen-inert gas stream at a somewhat lower temperature followed by heating the catalyst up to the reaction temperature subsequent to which the reaction mixture consisting of hydrocarbon, hydrogen and inert gas is introduced into the system [26-28]. Several different metallic and bimetallic catalysts can be used. Most commonly used catalysts are iron, cobalt, nickel and copper both in bulk and supported form. Lower hydrocarbons like methane, ethylene, acetylene or benzene and $\mathrm{CO}$ are the common source of carbon material. 
Despite great advances in synthesis methods and efforts at understanding the mechanism of nucleation and growth of CNFs, continuous production of CNFs has proven to be challenging and several issues need to be addressed. In recent years, a new method capable of synthesizing CNFs on a continuous scale called as the Vapor Grown Carbon Nanofibers (VGCNF) has emerged [29-32]. VGCNFs are produced by catalytic pyrolysis of hydrocarbons in the presence of a transition metal acting as the catalyst. Trace amounts of Sulfur is added to the feed to promote the formation of CNFs. Ferrocene dissolved in a suitable solvent or Iron Pentacarbonyl, $\mathrm{Fe}(\mathrm{CO})_{5}$ are commonly used catalyst sources. The organometallic catalyst decomposes forming clusters of Fe particles that act as nuclei for the formation and further growth of CNFs. The fibers coming out of the reactor along with the off-gases are trapped or separated using a series of cyclone separators or trap mechanisms located downstream of the reactor. The entire reactor assembly is enclosed within an electric furnace to supply sufficient heat to maintain the pyrolysis temperature of $1100-1200^{\circ} \mathrm{C}$. The characteristics of the fibers such as their thickness and length and hence their properties can be controlled by carefully manipulating the reactor operating conditions.

\subsection{Life cycle energy analysis}

This section describes the results of the life cycle energy analysis of carbon nanofiber production. CNF synthesis from hydrocarbons is considered for LCA and quantifying the life cycle energy requirements. The system boundary employed for the LCA of CNFs is depicted in figure 2. The inventory data for this case study is obtained directly from the published literature and complemented with mass and energy balances. Figure 3 presents a direct comparison of the life cycle energy requirements for CNF synthesis with traditional materials such as aluminum, steel, and polypropylene.

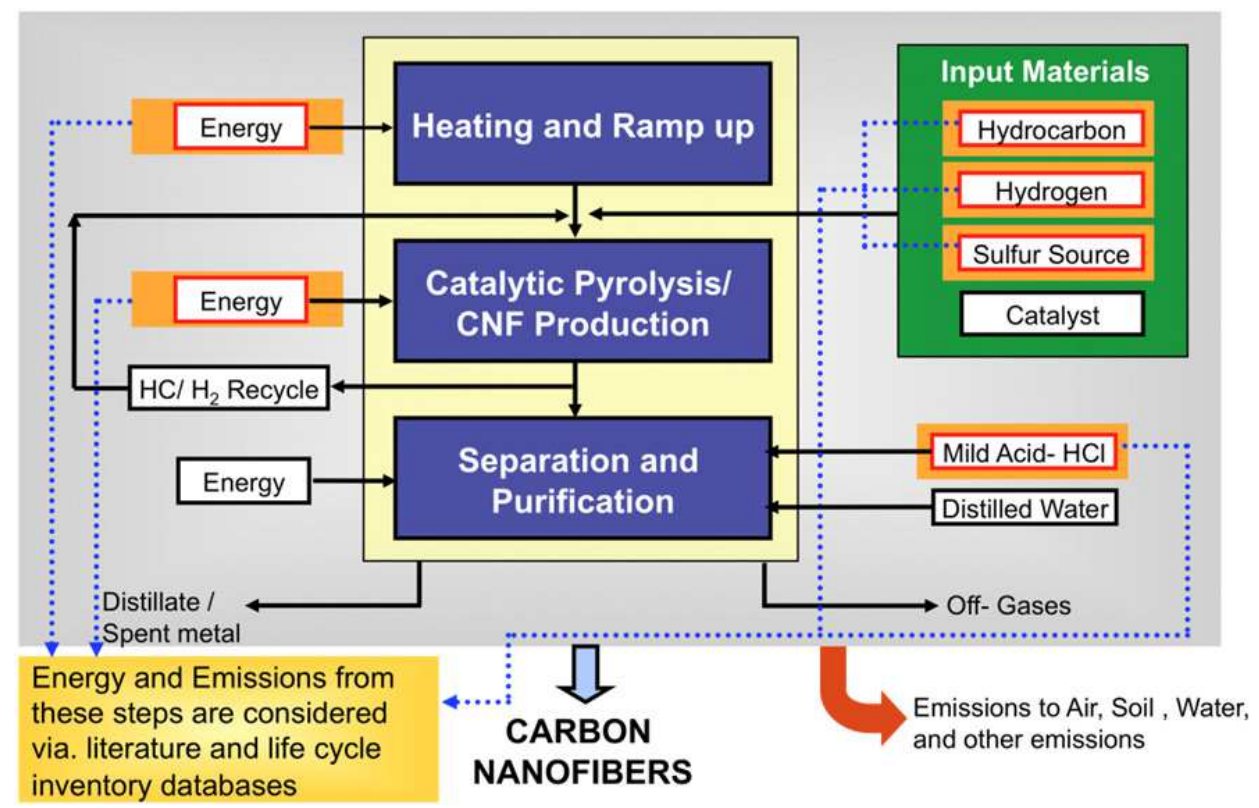

Fig. 2. LCA of Carbon Nanofibers: System Boundary. 
Three different feed stocks i.e. methane, ethylene and benzene are considered to quantify the life cycle energy intensities of VGCNFs. Different scenarios for catalyst and carrier gas recycle rates are evaluated to address uncertainty and evaluate the bounds on the life cycle energy consumption and emissions. Figure 3 presents a comparison of the life cycle energy requirements for $\mathrm{CNF}$ synthesis with those of traditional materials namely Aluminum, Steel and Polypropylene. Figure 3 shows that the life cycle of CNFs is energy intensive compared to traditional materials with the life cycle energy requirements for CNF synthesis ranging from $2872 \mathrm{MJ} / \mathrm{kg}$ for benzene feedstock to around $10925 \mathrm{MJ} / \mathrm{kg}$ for methane. Process energy consumption constitutes a large fraction of the overall life cycle energy requirements ranging from 79 percent to 86 percent for benzene and methane feedstocks respectively. This is primarily the resources consumed, mainly coal, to produce the electrical energy required to maintain the high decomposition temperature (around 1,100 to $1,200{ }^{\circ} \mathrm{C}$ ). A further comparison with aluminum, steel and polypropylene reveals that the life cycle of CNFs is energy intensive with the life cycle energy requirements being 86,30 and $119 \mathrm{MJ} / \mathrm{kg}$ for aluminum, steel and polypropylene respectively.

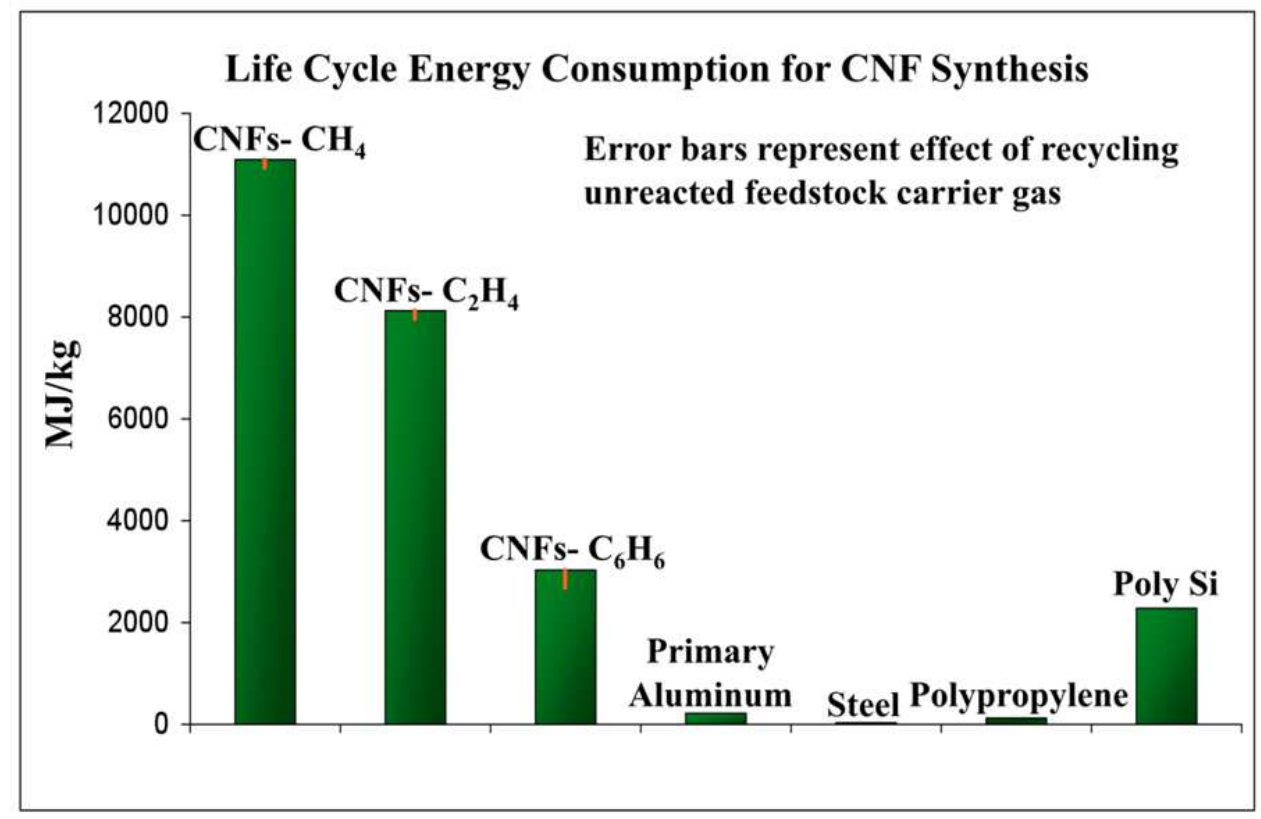

Fig. 3. Life Cycle Energy Analysis of Carbon Nanofibers.

The catalyst life cycle is not included due to the absence of life cycle inventory data for the catalyst thus resulting in lower bounds on the CNF life cycle energy requirements. Most industrial synthesis is carried out in the presence of a carrier gas that is generally $\mathrm{H}_{2}, \mathrm{NH}_{3}$ or some other inert gas. A sensitivity analysis is further carried out to study the influence of carrier gas recycle rates on the life cycle energy requirements. The results are displayed in Figure 3. Considering the methane feedstock, it is observed that even with complete recycling of the unreacted hydrocarbons and a $90 \%$ recycling of the hydrogen stream, the total energy consumption decreases from 10,925 MJ/kg to 10,778 MJ/kg. This corresponds 
to a $1.3 \%$ decrease in the overall life cycle energy requirements. In practice, such a high recycling rate is unlikely, and some of the unreacted materials may be burned for their fuel value. A similar trend is observed for ethylene feedstock, where complete recycling of the unreacted feed and $90 \%$ recycling of the hydrogen streams corresponds to a $2 \%$ reduction in the overall energy requirements. Thus, the process energy requirement still outweighs the energy savings due to material recycling. The energy required for separating unreacted hydrocarbons and hydrogen from the off-gases leaving the reactor is not accounted for here. Therefore, the numbers presented in figure 3 represent an upper bound on the energy savings from gas separation and system recycling.

\section{Global Warming Potential}

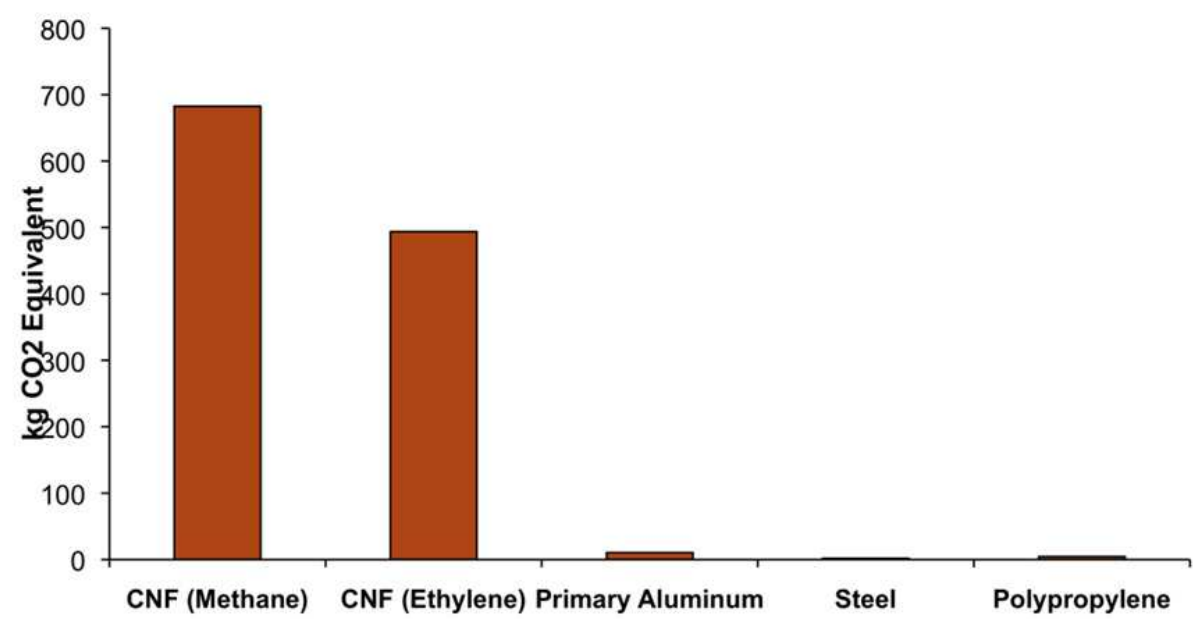

Fig. 4. Life Cycle Greenhouse Gas Emissions for CNF Synthesis.

On a per mass basis, the life cycle energy requirements for producing CNFs is 13 to 50 times what is required for producing primary aluminum. Several reasons can be attributed to this enormous difference. Firstly, processes required for manufacturing traditional materials are well-studied and have been optimized with respect to material and energy consumption over the last century or so. On the other hand, although researchers have been synthesizing CNFs on a laboratory scale, industrial synthesis of these nanoparticles remains a challenge. Secondly, industrial yields of these fibers are low even for continuous operations, i.e. in the range of $10-30 \%$ by weight of the feedstock. This again entails research efforts for process improvement to increase the yield of these nanoparticles to make them competitive with alternatives for a given application. Unless, these materials are used in a widespread way especially in large volume applications like polymer nanocomposites, it will be challenging to exploit the economies of scale and hence make these materials cost competitive with other alternatives. Researchers are also exploring the possibility of other low temperature processes like the Plasma enhanced CVD for the synthesis of CNFs [33]. These processes are 
expected to be operating at room temperatures thus eliminating the need for process heating. However, converting these laboratory scale processes to full-fledged continuous industrial operation will be challenging. Needless to mention, LCA of these new processes should be an integral component of research efforts in order to ensure that savings in energy and material resources are not offset by increased consumption in other phases of the life cycle.

\subsection{Environmental LCA of CNFs}

Two base cases are evaluated for CNF synthesis, one with methane and the other with ethylene as the feedstock. Both cases are considered to have hydrogen as the carrier gas in accordance with the current industrial schemes. Figure 4 shows a higher Global Warming Potential (GWP) for both methane and ethylene based CNFs when compared with aluminum, steel, and polypropylene on an equal mass basis. A closer look at figure 4 reveals that the GWP potential of $1 \mathrm{~kg}$ methane based CNF is equivalent to about $65 \mathrm{~kg}$ of primary aluminum whereas $1 \mathrm{~kg}$ of ethylene based CNF has a GWP equivalent of about $47 \mathrm{~kg}$ of steel. Similar trends are observed for other environmental impact categories and are discussed elsewhere [34]. The impact numbers for CNFs represent only lower bounds whereas those for traditional materials are expected to be more precise since detailed and relatively more complete inventory data is available in the literature for traditional materials. Release and impact of CNFs on humans and ecosystem species during manufacturing are not accounted in the analysis. Although the results presented in figure 4 are obtained based on conservative set of assumptions, they still represent important step towards the need and development of life cycle inventory modules for nanomaterials and nanoproducts.

\section{Carbon nanofiber polymer composites}

The comparisons of CNFs in section 2 with traditional materials are presented on an equal mass basis to get insight into the life cycle energy intensities and environmental burden. However, products based on CNFs might be greener than alternatives for a given application. Quantity will be the deciding factor and hence specific nanoproducts and applications need to be evaluated. One of the potential applications is the use of $\mathrm{CNFs}$ as reinforcement for polymer composites resulting in high strength polymer nanocomposites.

Traditionally conventional fiber composites consisting of glass or micron sized carbon fibers have been most commonly used for composite applications. Although traditional fiber reinforced plastics have good in-plane mechanical properties that are governed by conventional fibers, they have poor properties in the transverse and thickness directions characterized mainly by the properties of the polymer matrix. Failure of the polymer matrix between the fibers can take place under impact or shear. CNFs can provide benefits here by directly reinforcing the polymer matrix between the long fibers thereby enhancing the strength in the transverse and thickness directions. The result is a high strength composite that combines the advantages of conventional long fibers and CNFs. Besides enhancing the mechanical strength, CNFs can also impart desirable level of electrical conductivity to the polymer composites. Electrically conductive polypropylene composites (electrical resistivity $10,000 \mathrm{ohm}-\mathrm{cm}$ ) have been prepared with CNF loading levels of 3 volume percent in the polymer matrix [35]. Electrical resistivity values of as low as $100 \mathrm{ohm}-\mathrm{cm}$ have been 
reported for CNF reinforced epoxy composites at CNF loading content of 10 weight percent [36].

This section presents and discusses the life cycle energetic and Greenhouse Gas (GHG) impacts associated with the production and use of carbon nanofiber (CNF) PNCs. The use of PNCs in automotive body panels as a substitute for traditional materials is evaluated and compared with traditional materials. PNCs have enhanced mechanical properties, high strength-to-weight ratios, and are capable of offering specific functionalities such as desired level of electrical conductivity. These combinations of properties are making PNCs as one of the fastest growing plastic segment and an attractive alternative to conventional materials like steel and aluminum.

A typical life cycle of a PNC product is shown in figure 5. Several alternatives exist at each step in the complete life cycle. The selection of the polymeric resin depends on the application and hence the desired properties. Polypropylene (PP) and unsaturated polyester resin (UPR) are considered as the thermoplastic and thermosetting resins, respectively, as these have been widely studied in several nanocomposite experimental studies with respect to their mechanical and electrical properties. Specifically, both simple CNF and carbon nanofiber-glass fiber (CNF-GF) hybrid PNCs are evaluated and compared with steel for equal stiffness design. Life cycle inventory is developed based on published literature and best available engineering information.



Fig. 5. Typical Life Cycle of a Polymer Nanocomposite.

The analysis is performed at two levels. In the first level of analysis, the functional unit is the cradle to gate life cycle comparison of a automotive body panel with CNF and CNF-GF reinforced polymer composites for equal stiffness design. The mass and the corresponding 
thickness of the PNC material are estimated using Ashby's approach for equal stiffness design $[37,38]$. Use and end phase are not modeled for this analysis. In the second level of analysis, the life cycle energetic impact associated with the use of CNF and CNF-GF reinforced polymer composites vs steel in the body panels of a midsize car weighing $3300 \mathrm{lbs}$ (1497 kilogram) are estimated with the functional unit being 150,000 vehicle miles (277,800 kilometers) traveled. End of life phase of the automobile is not included in this analysis.

This study is a cradle to gate study as it does not include the end of life issues specific to $\mathrm{CNF}$ reinforced polymer composite materials primarily because of the lack of quantifiable information about the recovery of CNF and GF from thermoplastic and thermoset polymer composite materials. Comparison of a PNC auto body panel for equal stiffness design evaluates the life cycle energetic impact first without including the use phase. The case study involving the use of CNF and CNF-GF reinforced PNCs vs. steel in the body panels of a midsize car goes a step further by including the vehicle use phase but still does not consider the end of life phase. Including the end of life considerations may not change the overall conclusions of this study.

The basis for comparison is the equal stiffness design of the components. This is justified on the basis that for structural and automotive applications, the component is assumed to have sufficient strength once it meets the stiffness criteria. Although this criteria may be true for automotive applications, but other considerations such as the impact properties may also influence the final material selection. Impact energy, an indicator of energy absorbing capacity is shown to decrease with the increasing content of CNFs in long fiber thermoplastic materials [35].

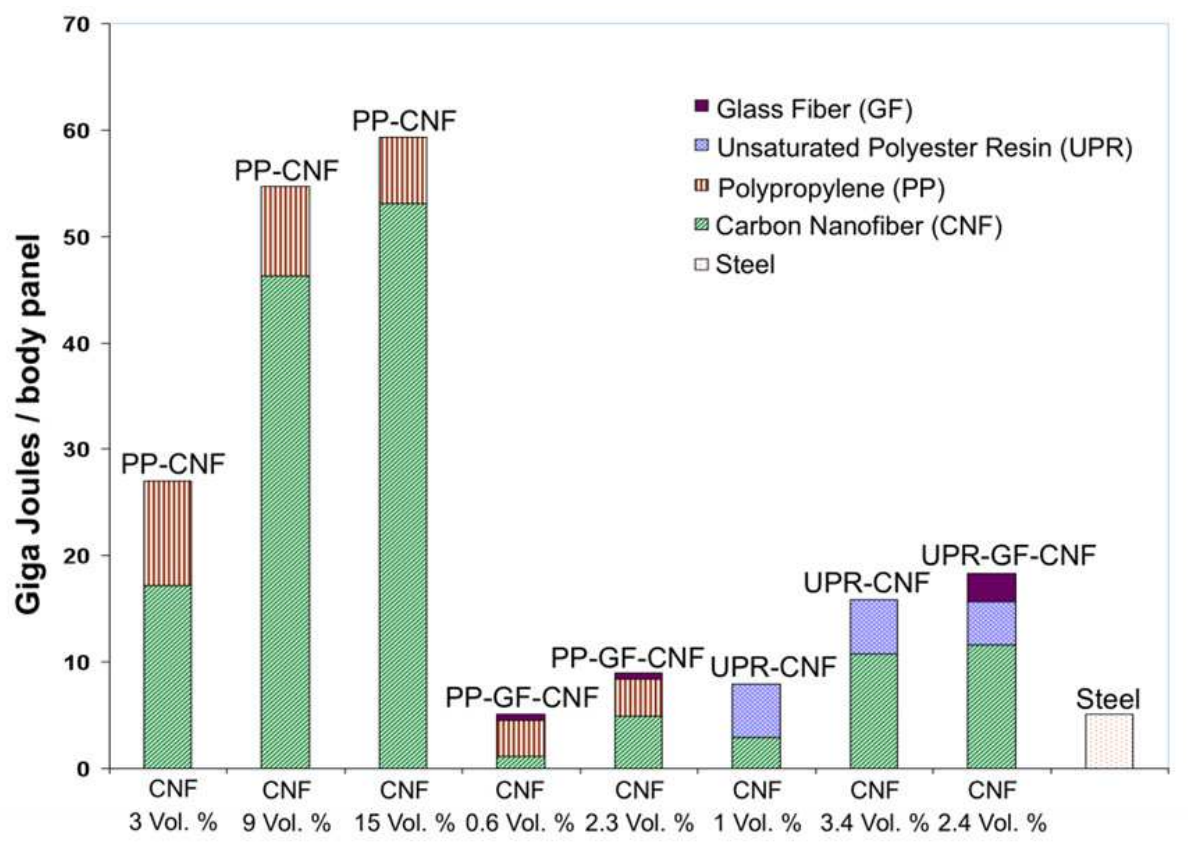

Fig. 6. Life cycle energy comparison of polymer nanocomposites with steel for equal stiffness design. 
Primary weight savings for the automotive body panels are calculated directly using Ashby's approach. Secondary weight savings of $0.5 \mathrm{~kg} / \mathrm{kg}$ of primary weight savings are considered resulting from downsizing of the chassis and auxiliaries. Based on the different values previously used in comparing aluminum-intensive vehicles with steel, a sensitivity analysis is performed by considering a range of $0.5-1 \mathrm{~kg}$ of secondary weight savings per $\mathrm{kg}$ of primary weight reduction [39-41]. Improvement in fuel economy relative to vehicle with steel body panels is calculated using the sedan equivalent estimation proposed and used previously [39, 42, 43].

$$
\mathrm{FE}_{2}=\mathrm{FE}_{1}\left(\frac{\mathrm{m}_{1}}{\mathrm{~m}_{2}}\right)^{0.72}
$$

where $\mathrm{FE}_{\mathrm{i}}$ is the fuel economy of vehicle $\mathrm{i}$ and $\mathrm{m}_{\mathrm{i}}$ is the mass of vehicle $\mathrm{i}$.

The results of a cradle-to-gate (excludes use phase) life cycle comparison of PNCs vs. steel for equal stiffness of the components are presented in Figure 3. Figure 3 reveals that on a cradle-to-gate basis, CNF-based polymer composite auto body panels are 1.6-12 times more energy intensive when compared with steel. It is concluded that the product use phase might govern whether the high upstream manufacturing energy can be offset during the use phase to realize any life cycle energy savings.

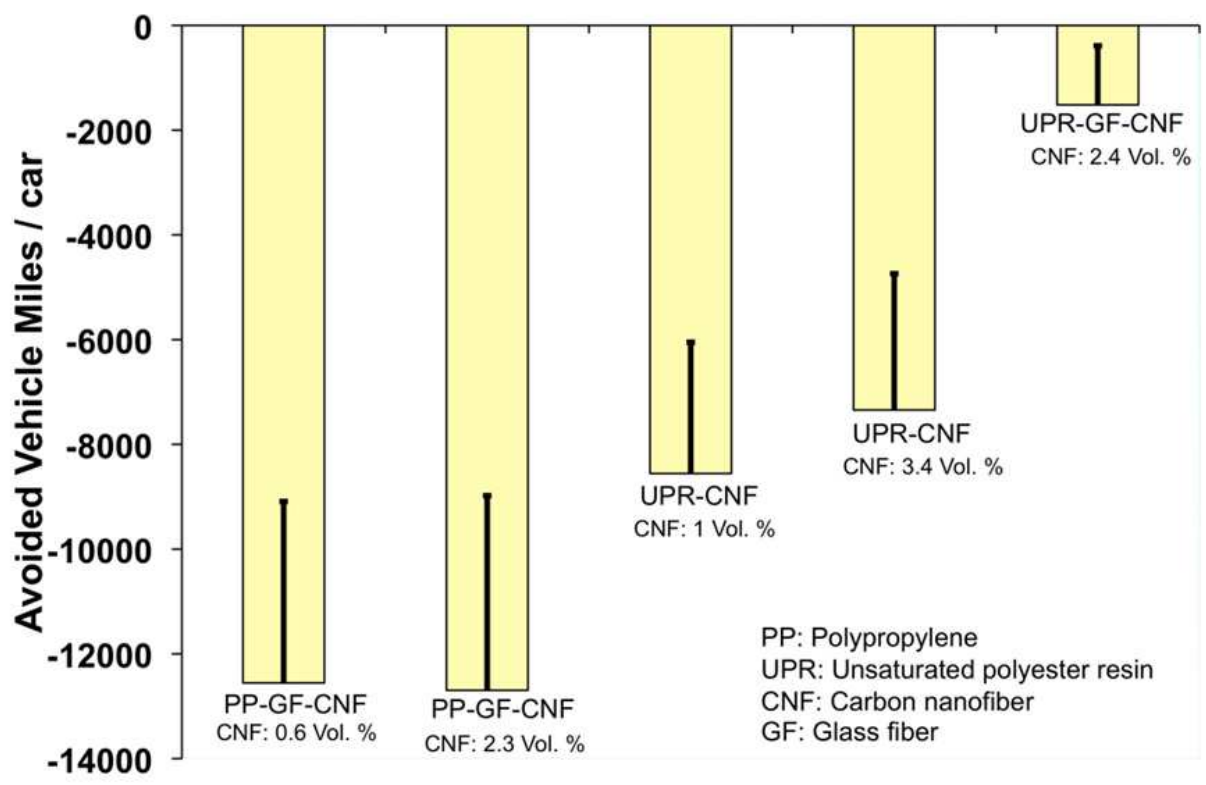

Fig. 7. Percentage savings in fuel gasoline consumption relative to steel only for use phase in auto body panels.

The use of CNF reinforced nanocomposites in body panels of light-duty vehicles is further evaluated. The life cycle of a midsize automobile with CNF reinforced nanocomposite body panels is evaluated and compared relative to conventional steel panels. The results are shown in figure 7. Overall for the range of CNF compositions and scenarios investigated, 
lifetime savings in fossil energy consumption are observed for PNC-based body panels relative to steel. Other factors such as cost, toxicity impact of CNF, and end-of-life issues specific to CNFs need to be considered to evaluate the final economic and environmental performance of CNF reinforced PNC materials.

The distribution of the life cycle energy consumption along different phases in the life cycle for CNF reinforced polymer composite automotive body panel is depicted in figure 8 . Figure 8 does not include the use phase of vehicle. It is observed that majority of the life cycle energy impact results from the life cycle of carbon nanofiber production especially for polymer composites with higher loading ratios of CNFs. Among thermoset based PNCs, CNF constitute 38-68 percent of the cradle to gate life cycle energy consumption. The next highest impact results from the production of the polymeric resins followed by glass fibers.



Fig. 8. Distribution of life cycle energy consumption for the manufacture of CNF based polymer composite automotive body panels. Vehicle use phase is not included.

\section{Toxicological impact of CNFs}

The previous sections highlighted the life cycle energetic impacts associated with CNFs and their use in automotive body panels. It also highlighted how the unique electrical, mechanical, and thermal properties [44], makes them extremely appealing to new technologies such as electronics, energy applications, and automotive applications [45]. However, the same properties that make CNFs attractive also raise concerns about their toxicity impacts. Because of the distinctive size and shape of CNFs, human toxicological 
reactions may vary as a result of the different modes of exposure, specifically inhalation, dermal, and consumption. The behaviors of nanomaterials are not the same as their bulk material behavior; therefore regulated material safety data sheets (MSDS) should not be regarded as a safety precaution when handling nanomaterials. This is especially important for the people who work in close proximity to these materials since they have a higher risk of inhalation, which could lead to significant respiratory effects [46].

There are very few toxicological studies on carbon nanotubes, and even less so for CNFs. There is still a need for better and more sophisticated studies that understand the health concerns of CNFs before they can be utilized for large volume applications. CNFs are known for their high aspect ratio, which represents a long and narrow shape [47, 48]. This unique shape and different aggregation scenarios, varied between bundle sizes and rope formations, can render different toxicological results, a problem for consistent toxicological understanding [48]. One research study compares carbon nanotubes to carbon fibers and carbon black particles, focusing on the ratio between nanoparticle size and surface area to the corresponding toxicity in cells. The toxicity results show that carbon black particles, a commercial example would be coal mine dust, and carbon fibers, which have a very similar resemblance to asbestos, were more toxic than the carbon nanotubes [47]. The study could only conclude that the toxicity and morphology reaction among the lung cells were not different depending on the carbon-based size, but that there was an obvious sensitivity reaction, where carbon black particles and carbon fibers had more cell response than carbon nanotubes [47].

Another study looked at both single-wall and multi-wall carbon nanotubes and their consequential dermal and pulmonary exposure routes [48]. In general, the aforementioned high aspect ratio is a large concern for the toxicity of nanomaterials, especially because as the particles and fibers get smaller, they have increased potential to cause harm [47, 48]. The study continues to divulge the issues of carbon particles and fibers, stating that fibers are much more pathogenic through inhalation and respiration modes of exposure than others [48]. Asbestos is the most widely researched fiber material and is used as a benchmark for toxicological studies on CNFs. Three characteristics were established in the study pertaining to CNFs and their toxicity potential in respiratory situations and have been supported by other prominent studies.

The size of fibers is important for determining how they will react and transport within the lung cells. Long fibers $(>15 \mu \mathrm{m})$ can have severe inflammatory reactions if they are narrow enough $(<5 \mu \mathrm{m})$ [48]. Metal and chemical compositions of individual fibers have their own toxicological reactivity within the cell [47-50]. Iron (Fe), cobalt (Co), and nickel (Ni) are the most widely used metal catalysts in the preparation of carbon nanotubes, which are built upon CNFs [50]. There is not conclusive evidence that states which metal catalyst induces the most adverse effects, but there is a difference between pure carbon nanotubes and carbon nanotubes with metal content $[49,50]$.

There is fear associated with the toxicology of CNFs because they have a strong resemblance to asbestos fibers and do not possess the quality to biodegrade [51]. Biopersistance is important evidence that CNFs can lead to adverse health effects, however it is difficult to quantify the behavior of these fibers as their size and chemical composition vary significantly [50]. Unfortunately, it is much easier to study the immediate effects of nanomaterials than the long-term or natural exposure effects.

Future research needs to take into account various nanomaterial point of views to gain a better, well rounded perspective of how nanomaterials react naturally. The medical world, 
including pharmaceuticals and medical devices comprised of nanomaterials, is one field that needs extra precaution [45, 52]. The life cycle of nanomaterials is also necessary for understanding how nanomaterial products and processes will influence the environment in end of life scenarios. The long-term effects on the environment are much harder to study and understand because of the little known knowledge of nanomaterial behavior and the difficulty of mimicking the natural environment in a laboratory. There is potential for environmental toxicity caused by nanomaterials, another reason why many are hesitant of the wide scale use of nanomaterials.

\section{Summary}

Engineered nanomaterials such as CNFs with their unique material properties offer the potential for reducing the material and energy intensity of engineered products and processes. While toxicological studies of engineered nanomaterials is essential, holistic understanding of nanomaterials and resulting nanoproducts via LCA is critical to evaluate the benefits of emerging nanoproducts before declaring them as superior to conventional products. LCA can help in providing metrics for environmental evaluation of potential nanoproducts vs. alternatives. LCA based on biophysical quantification of resource use can offer preliminary insight into the broader impact of emerging nanotechnologies. The LCA of CNFs discussed in this chapter highlighted the hugely energy intensive nature of the production processes of CNFs. However, it is difficult to reach any conclusions about the environmental impact of nanoproducts based on such engineered nanomaterials without taking into account their complete life cycle. A case study involving the use of CNF reinforced PNCs in the body panels of automobiles highlights that the use of PNCs with lower CNF loading ratios has the potential for net life cycle energy savings relative to steel owing to improved fuel economy benefits. Thus, evaluation of potential nanoproducts on functional unit basis is essential. Such comparisons can help identify if the increased upstream production energy requirements are offset by savings during the use phase of the product or not. Besides, for certain products such as automotive or aerospace components use phase might dominate the energy use across the complete life cycle and hence may offer net life cycle energy savings. In other cases, the manufacturing phase might play a more significant role and hence offset any potential energy or environmental benefits achieved in other life cycle phases. Besides, end-of-life challenges such as recovery and recycle specific to engineered nanomaterials might be encountered for certain nanoproducts. In the absence of detailed environmental fate and transport, scenario analysis might help in screening different alternatives. Besides, scenario analysis coupled with LCA can also provide novel insights about the long-term impact of nanomaterial use across the economy. For example, the quantity of individual nanomaterials in specific products might be small but overall can have huge material and energy impact if used in large volume applications. In such cases, the resource efficiency of the upstream nanomaterial manufacturing stage might alone govern the sustainability of potential nanotechnologies.

\section{References}

[1] Project on Emerging Nanotechnologies, W.W.C. Nanotechnology consumer products inventory [cited 2011 January 30]; Available from: http://www.nanotechproject.org/inventories/consumer. 
[2] Schmid, K. and M. Riediker, Use of nanoparticles in Swiss industry: a targeted survey. Environmental science \& technology, 2008. 42(7): p. 2253-2260.

[3] Gogotsi, Y., Carbon nanomaterials. 2006: CRC.

[4] De Jong, K.P. and J.W. Geus, Carbon nanofibers: catalytic synthesis and applications. Catalysis Reviews, 2000. 42(4): p. 481-510.

[5] Mordkovich, V., Carbon nanofibers: a new ultrahigh-strength material for chemical technology. Theoretical Foundations of Chemical Engineering, 2003. 37(5): p. 429-438.

[6] Dreher, K.L., Health and environmental impact of nanotechnology: toxicological assessment of manufactured nanoparticles. Toxicol Sci, 2004. 77(1): p. 3-5.

[7] Maynard, A.D., et al., Safe handling of nanotechnology. Nature, 2006. 444(7117): p. 267-9.

[8] Thomas, K. and P. Sayre, Research strategies for safety evaluation of nanomaterials, Part I: evaluating the human health implications of exposure to nanoscale materials. Toxicol Sci, 2005. 87(2): p. 316-21.

[9] Maynard, A., Nanotechnology: the next big thing, or much ado about nothing? Annals of Occupational Hygiene, 2006. 51(1): p. 1.

[10] Powers, K.W., et al., Research strategies for safety evaluation of nanomaterials. Part VI. Characterization of nanoscale particles for toxicological evaluation. Toxicol Sci, 2006. 90(2): p. 296-303.

[11] Thomas, T., et al., Research strategies for safety evaluation of nanomaterials, part VII: evaluating consumer exposure to nanoscale materials. Toxicol Sci, 2006. 91(1): p. 149.

[12] Initiative, T.N.N. Environmental, health, and safety research needs for engineered nanoscale materials. 2006 [cited 2011 January 31]; Available from: http://www.nano.gov/NNI_EHS_research_needs.pdf.

[13] Society, T.R. Nanoscience and nanotechnologies: opportunities and uncertainties. 2004 [cited 2011 January 31]; Available from: http://www.nanotec.org.uk/finalReport.htm.

[14] W. Kl“opffer, M.A.C., P. Frankl, R. Heijungs, A. K"ohler, and S.I. Olsen. Nanotechnology and Life Cycle Assessment. A systems approach to Nanotechnology and the environment Synthesis of Results Obtained at a Workshop Washington, DC 2-3 October 2006. 2007 [cited 2011 January 31].

[15] Theis, T. The Life Cycle of Nanomanufacturing Technologies. . in Interagency Environmental Nanotechnology Grantees Workshop. 2009. Tampa, FL.

[16] Curran, M.A., Environmental life-cycle assessment. 1996, New York: McGraw-Hill. 1 v. (various pagings).

[17] Graedel, T.E., Streamlined life-cycle assessment. 1998, Upper Saddle River, NJ: Prentice Hall. $x, 310$ p.

[18] Bare, J. and T. Gloria, Critical analysis of the mathematical relationships and comprehensiveness of life cycle impact assessment approaches. Environ. Sci. Technol, 2006. 40(4): p. 1104-1113.

[19] Rebitzer, G., et al., Life cycle assessment Part 1: Framework, goal and scope definition, inventory analysis, and applications. Environment International, 2004. 30(5): p. 701720 .

[20] United States. Environmental Protection Agency. Office of Air Quality Planning and Standards., Life-cycle impact assessment : a conceptual framework, key issues, and summary of existing methods. 1995, Research Triangle Park, NC: U.S. Environmental 
Protection Agency, Office of Air Quality Planning and Standards. 1 v. (various pagings).

[21] Bauer, C., et al., Towards a framework for life cycle thinking in the assessment of nanotechnology. Journal of Cleaner Production, 2008. 16(8-9): p. 910-926.

[22] Russell, R. and R. Cresanti, Environmental Health and Safety Research Needs for Engineered Nanoscale Materials. 2006.

[23] Theis, T.L., et al., A life cycle framework for the investigation of environmentally benign nanoparticles and products. physica status solidi (RRL) ñRapid Research Letters.

[24] Dowling, A., et al., Nanoscience and nanotechnologies: opportunities and uncertainties. London: The Royal Society E The Royal Academy of Engineering Report, 2004.

[25] Rodriguez, N., A review of catalytically grown carbon nanofibers. Journal of Materials Research;(United States), 1993. 8(12).

[26] Kim, M., N. Rodriguez, and R. Baker, The interaction of hydrocarbons with copper--nickel and nickel in the formation of carbon filaments. Journal of Catalysis, 1991. 131(1): p. 60-73.

[27] Lim, S., et al., Selective synthesis of thin carbon nanofibers: I. Over nickel-iron alloys supported on carbon black. Carbon, 2004. 42(8-9): p. 1765-1781.

[28] Takehira, K., et al., Catalytic growth of carbon fibers from methane and ethylene on carbon-supported Ni catalysts. Applied Catalysis A: General, 2005. 283(1-2): p. 137145.

[29] Chambers, A., N. Rodriguez, and R. Baker, Influence of copper on the structural characteristics of carbon nanofibers produced from the cobalt-catalyzed decomposition of ethylene. Journal of materials research, 1996. 11(02): p. 430-438.

[30] Fan, Y.Y., et al., Tailoring the diameters of vapor-grown carbon nanofibers. Carbon, 2000. 38(6): p. 921-927.

[31] Tibbetts, G.G., et al., Role of sulfur in the production of carbon fibers in the vapor phase. Carbon, 1994. 32(4): p. 569-576.

[32] Tibbetts, G.G., D.W. Gorkiewicz, and R.L. Alig, A new reactor for growing carbon fibers from liquid-and vapor-phase hydrocarbons. Carbon, 1993. 31(5): p. 809-814.

[33] Minea, T., et al., Room temperature synthesis of carbon nanofibers containing nitrogen by plasma-enhanced chemical vapor deposition. Applied physics letters, 2004. 85: p. 1244.

[34] Khanna, V., B.R. Bakshi, and L.J. Lee, Carbon nanofiber production: Life cycle energy consumption and environmental impact. Journal of Industrial Ecology, 2008. 12(3): p. 394-410.

[35] van Hattum, F., et al., Conductive long fibre reinforced thermoplastics by using carbon nanofibres. Plastics, Rubber and Composites, 35, 2006. 6(7): p. 247-252.

[36] Choi, Y., et al., Mechanical and physical properties of epoxy composites reinforced by vapor grown carbon nanofibers. Carbon, 2005. 43(10): p. 2199-2208.

[37] Ashby, M., Materials selection in mechanical design. 2005: Butterworth-Heinemann.

[38] Ashby, M. and D. Jones, Engineering materials 1. An introduction to their properties and applications. 1980: Pergamon Press, Oxford, England.

[39] Lloyd, S.M. and L.B. Lave, Life cycle economic and environmental implications of using nanocomposites in automobiles. Environ Sci Technol, 2003. 37(15): p. 3458--3466.

[40] Stodolsky, F., et al., Life-cycle energy savings potential from aluminum-intensive vehicles. 1995. 
[41] Das, S., The life-cycle impacts of aluminum body-in-white automotive material. JOM Journal of the Minerals, Metals and Materials Society, 2000. 52(8): p. 41-44.

[42] MacLean, H. and L. Lave, Environmental implications of alternative-fueled automobiles: Air quality and greenhouse gas tradeoffs. Environ. Sci. Technol, 2000. 34(2): p. 225-231.

[43] Lave, L., Conflicting objectives in regulating the automobile. Science, 1981. 212(4497): p. 893.

[44] Lam, C.-w., et al., A Review of Carbon Nanotube Toxicity and Assessment of Potential Occupational and Environmental Health Risks. Critical Reviews in Toxicology, 2006. 36(3): p. 189-217.

[45] Illuminato, I., G. Miller, and L. Matthes, Nanotechnology, Climate, and Energy: Overheated Promises and Hot Air? 2010, Friends of the Earth International US edition. p. 88.

[46] Colvin, V.L., The potential environmental impact of engineered nanomaterials. Nat Biotech, 2003. 21(10): p. 1166-1170.

[47] Magrez, A., et al., Cellular Toxicity of Carbon-Based Nanomaterials. Nano Letters, 2006. 6(6): p. 1121-1125.

[48] Smart, S.K., et al., The biocompatibility of carbon nanotubes. Carbon, 2006. 44(6): p. 1034-1047.

[49] Poland, C.A., et al., Carbon nanotubes introduced into the abdominal cavity of mice show asbestos-like pathogenicity in a pilot study. Nat Nano, 2008. 3(7): p. 423-428.

[50] Pulskamp, K., S. Diabatè, and H.F. Krug, Carbon nanotubes show no sign of acute toxicity but induce intracellular reactive oxygen species in dependence on contaminants. Toxicology Letters, 2007. 168(1): p. 58-74.

[51] Kostarelos, K., The long and short of carbon nanotube toxicity. Nat Biotech, 2008. 26(7): p. 774-776.

[52] Lacerda, L., et al., Carbon nanotubes as nanomedicines: From toxicology to pharmacology. Advanced Drug Delivery Reviews, 2006. 58(14): p. 1460-1470. 


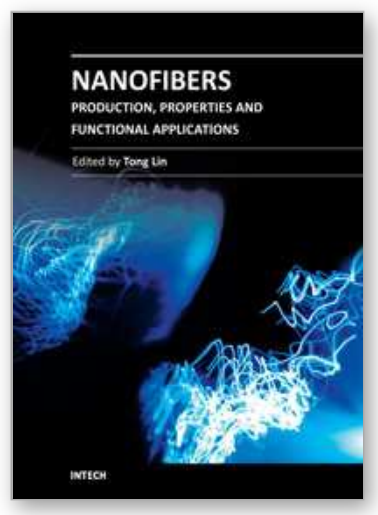

\author{
Nanofibers - Production, Properties and Functional Applications \\ Edited by Dr. Tong Lin
}

ISBN 978-953-307-420-7

Hard cover, 458 pages

Publisher InTech

Published online 14, November, 2011

Published in print edition November, 2011

As an important one-dimensional nanomaterial, nanofibers have extremely high specific surface area because of their small diameters, and nanofiber membranes are highly porous with excellent pore interconnectivity. These unique characteristics plus the functionalities from the materials themselves impart nanofibers with a number of novel properties for advanced applications. This book is a compilation of contributions made by experts who specialize in nanofibers. It provides an up-to-date coverage of in nanofiber preparation, properties and functional applications. I am deeply appreciative of all the authors and have no doubt that their contribution will be a useful resource for anyone associated with the discipline of nanofibers.

\title{
How to reference
}

In order to correctly reference this scholarly work, feel free to copy and paste the following:

Vikas Khanna and Nikki Campion (2011). Carbon Nanofibers: Evaluation of Life Cycle Environmental Impacts, Nanofibers - Production, Properties and Functional Applications, Dr. Tong Lin (Ed.), ISBN: 978-953-307-420-7, InTech, Available from: http://www.intechopen.com/books/nanofibers-production-properties-and-functionalapplications/carbon-nanofibers-evaluation-of-life-cycle-environmental-impacts

\section{INTECH}

open science | open minds

\section{InTech Europe}

University Campus STeP Ri

Slavka Krautzeka 83/A

51000 Rijeka, Croatia

Phone: +385 (51) 770447

Fax: +385 (51) 686166

www.intechopen.com

\section{InTech China}

Unit 405, Office Block, Hotel Equatorial Shanghai

No.65, Yan An Road (West), Shanghai, 200040, China

中国上海市延安西路65号上海国际贵都大饭店办公楼 405 单元

Phone: +86-21-62489820

Fax: +86-21-62489821 
(C) 2011 The Author(s). Licensee IntechOpen. This is an open access article distributed under the terms of the Creative Commons Attribution 3.0 License, which permits unrestricted use, distribution, and reproduction in any medium, provided the original work is properly cited. 